\title{
Chapter 9 \\ Modeling Vulnerable Urban Populations in the Global Context of a Changing Climate
}

\author{
Vijay Lulla, Austin Stanforth, Natasha Prudent, Daniel Johnson, \\ and George Luber
}

\section{Introduction}

Climate change, an increase in overall average temperature and frequency of extreme weather events, will influence human populations and exert stress on the current and future built environment. Most contemporary climate models indicate that climate change will have heterogeneous impact globally, and its effects are expected to be more severe in urban centers. This is due to the increased density of human populations, materials used to construct the urban area, and land-use practices therein [44]. There are numerous health stressors present in urban locations, such as the urban heat island (UHI) effect and pollution, despite proximal access to health services. Understanding the effects of climate change on human health will become a central focus of the public health community in the twenty-first century. The anticipated consequences of climate change are not yet fully realized, but increased local risk disparities are apparent and will require a multidisciplinary paradigm of investigation to successfully identify vulnerable populations and mitigate environmental and social impacts. This chapter highlights several environmental and disease processes that are expected to be impacted by a changing climate. Following this introduction, a methodology of determining vulnerability using state-of-the-art data acquisition and computational techniques will be illustrated. Therefore, this chapter aims to be an introduction to climate effects on human health and to the vulnerability modeling of these effects.

\footnotetext{
V. Lulla, Ph.D. $(\varangle) \bullet$ A. Stanforth, M.S. $(\bowtie) \bullet$ D. Johnson, Ph.D.

Indiana University Purdue University Indianapolis, Institute for Research on Social Issues, Indianapolis, IN, USA

e-mails: vlulla@iupui.edu; austin.stanforth@gmail.com

N. Prudent, M.P.H. • G. Luber, Ph.D.

Centers for Disease Control and Prevention, Atlanta, GA, USA
} 


\section{Urbanization and Climate}

As the world's population migrates from rural to more urban settings, understanding how urban forms (dense or spread out) alter local climate, and how climate change will uniquely impact urban environments, is critical. First, it is essential to understand the difference between weather and climate. Weather looks at short-term daily or monthly variations in precipitation, wind, and temperature within predefined geographical areas. Climate focuses on decadal trends of the above variables within those same or larger areas. Climate is influenced by energy added to and released from Earth's system over time, which influences weather patterns. The Sun provides energy to the system that is either radiated back into outer space or absorbed by oceans and land cover. Alterations in normal climate patterns can be attributed to disruptions in this energy balance. For example, increases in light-colored aerosols in the atmosphere serve to reflect solar radiance, decreasing the amount of energy that enters Earth's system; on the other hand, increasing amounts of greenhouse gases, concrete roads, and buildings serve to increase the amount of heat absorbed in Earth's system [51]. While large-scale energy fluxes influence global climate, urban centers can alter local energy budgets through UHIs and wind patterns to further impact local climate [45]. Increased commercial density, residential density, impervious surfaces (such as roads, parking lots, and other concrete features), and a reduction of green vegetation or large bodies of water all serve to modify temperature, precipitation, and wind, in comparison to rural areas [23]. Thus, climate investigations can be performed at either a global or urban scale.

The UHI effect is the phenomenon by which temperature in an urban setting is higher relative to the surrounding rural settings [1]. This steep gradient of temperature is driven by the man-made characteristics of urban areas. The composition of buildings and the decrease in cooling vegetation cause the retention of daytime heat. This heat is then radiated back out into the ambient air during the night, raising the local ambient temperature [68]. The steepness of the temperature gradient varies by climate zone, with temperate latitude cities seeing nighttime increases of $1-5{ }^{\circ} \mathrm{C}$, while more tropical cities, during the dry season, exhibit gradients as high as $10{ }^{\circ} \mathrm{C}$ [37]. The size and density of the city also influence the intensity of the UHI effect [46]. Higher levels of light-colored aerosol-based pollutants, such as pure sulfates or salt particles, can have a cooling effect by blocking solar radiation. However, lower albedo or surface reflection levels within urban areas trap heat and offset any potential urban cooling experienced during altered radiation fluxes. In addition to lower albedo, larger street canyons typical of denser cities modify the intensity of urban temperatures through changes in wind speed and advection [23, 45].

Although the research is still developing, the UHI effect may also serve as one of the main drivers of changes in urban precipitation patterns [5, 6, 9, 40]. Warmer temperatures associated with the UHI effect increase thermal convection, leading to lower convergence $[45,63]$. Cool, moist air is pulled toward the city for the formation of rain-bearing clouds downwind [9]. Intensification of precipitation has similarly been linked to urban canyons and the proximity of coastal bodies and rivers. 
In addition, air pollution creates favorable conditions for water droplets to form and grow $[4,40]$. Understanding precipitation dynamics over large cities is very complex, and studies show conflicting reports on the role urban form plays in changes to precipitation patterns. As human populations continue to expand the built environment through urban migration, understanding how urban forms influence local climate is necessary to assess climate change-associated negative health consequences within the context of urbanization.

\section{Global Climate Change, Built Environment, and Health}

Oppressive climates influence the health of human populations in various adverse ways. According to current climate change models, it is very likely that extreme heat events (EHEs) will become more severe and longer in duration. Future exposure to extreme heat has a significant impact on morbidity and mortality. One study estimates that by 2020 — assuming current emission trends continue - 44 large US cities will experience an increase of 2,260 excess summer deaths, and by 2050 those urban areas could experience total excess deaths of 3,190-4,478 [31]. In addition to the commonly experienced heat stroke, heat exhaustion, heat cramps, and dehydration cases, heat can also contribute to the formation of blood clots, aggravate chronic pulmonary conditions, cardiac conditions, kidney disorders, and psychiatric illnesses [67].

Climate change is also expected to exacerbate further poor air quality and pollution within urban centers. Ozone, particulate matter $2.5 \mu \mathrm{m}$ in diameter (PM2.5), and aeroallergens are expected to be among the major air pollutants. Ozone formation increases with higher temperatures and increased sunlight [15]. Similarly, large particulate formation is partly dependent on temperature and humidity; thus, concentrations may increase with warmer temperatures [8]. Aeroallergens, like pollen, are airborne particles that elicit an allergic response in sensitive persons [34]. The warmer temperatures and increased carbon dioxide levels characteristic of urbanization and climate change contribute to earlier flower blooming and thus earlier and longer pollen seasons [58]. However, whether forecasted changes in the pollen season will result in an increase in allergic disease is yet to be definitively determined [34]. Health effects associated with poor urban air quality that climate change may exacerbate include decreased lung function, heart attack, arrhythmias, increased hospital admissions for respiratory illnesses (e.g., asthma, pneumonia, and rhinitis), and premature mortality $[2,8,14,15,20,24,39,41,43,49,50,55,57]$.

Heavy rainfall events are expected to become more frequent and intense with climate change. This imposes an additional burden on already stressed urban infrastructure-particularly water and sanitation systems - and increases the potential for the spread of disease. Data on US waterborne disease outbreaks from 1948 to 1994 suggest a significant association with levels of extreme precipitation [10]. This relationship is not well understood, but is principally attributed to increased runoff transporting elevated levels of microorganisms (e.g., Giardia, Cryptosporidium) 
into surface water and groundwater [17]. The data also indicate that during heavy rainfall events, urban water sources are particularly susceptible to contamination due to overflows in pipes that transport both sewage and storm water (i.e., combined system overflows) [54].

Warmer temperatures and changing precipitation patterns characteristic of climate change may also alter the distribution of disease-carrying vectors and zoonoses. For example, rising temperatures may increase the rate of dengue virus replication in host mosquitoes [21]. Tick distribution is also highly correlated with temperature and humidity. It is suspected that change in climate may affect incidence of tick-borne diseases, such as Lyme disease and Rocky Mountain spotted fever [21]. West Nile virus and Saint Louis encephalitis virus are associated with drought-like conditions and high temperatures [21]. However, despite known correlations between temperature, precipitation, and distribution of vectors and zoonoses, increases in transmission rates are affected by a host of other ecological factors $[13,18,38,42,47,52,59,66]$. The public health impact of changes to the distribution of disease-carrying vectors and zoonoses depends on non-climatic factors as well, such as access to prevention methods (e.g., air conditioning and sealed structures) [51]. Better holistic urban climate change models need to be developed before we can truly identify the best methods for dealing with the negative effects of climate change [18].

The emerging threats of climate change within the context of urban health provide an engaging framework for addressing anticipated health stressors [16]. The field of public health includes a continually evolving evidence-based body of tools, such as vulnerability assessments, that identify segments of the population facing the greatest risk of direct exposure. These tools can serve to promote resilience and form sustainable policies in communities disproportionately burdened with negative health consequences associated with climate change and urban development.

\section{Vulnerability and Urban Population Health}

\section{New Spatial Vulnerability Assessment Approaches}

Population vulnerability results from the inability of a population to cope with a hazard due to increased sensitivity, susceptibility, or lack of adaptive capacity [22, 23]. Within the public health literature, an understanding of vulnerability lies within the environmental justice thesis, which suggests that risks incurred from environmental hazards are greater among marginalized populations [22]. The study of population vulnerability, then, seeks to identify conditions that render certain populations more prone to exposures and measure the adaptive capacity of the population within a socioeconomic context [11].

Traditionally, population vulnerability is the cumulative negative pressure exerted by biophysical and social ramifications. Social vulnerability is composed of variables derived from the social or economic environment, encompassing age, 
education, income, gender, ethnic/racial composition, and population density of individuals in the population. Biophysical vulnerability includes risk to direct environmental exposures, such as extreme heat and flooding. It also includes built environment factors, such as the UHI effect, and other land-use patterns that exacerbate biological risks. Social vulnerability is well-researched, while assessments of biophysical vulnerability are a more recent endeavor [65]. Integrating social and biophysical risk factors into an assessment of population vulnerability allows for a more cohesive and useful understanding of how climate change will influence populations in expanding urban environments.

It is at the finer scale within cities that intra-urban vulnerability becomes most pronounced, i.e., social and biophysical risks are disproportionally distributed across an urban area [61]. For example, a vulnerability study in Phoenix, Arizona, demonstrated that pockets of communities within the study area faced greater exposure to heat stress, due to higher social and biophysical vulnerabilities (e.g., age and less vegetation), than the surrounding communities [22]. Spatial distribution of vulnerable populations overlapping with climate hazard segments within a city has yet to be fully explored [28]. Less utilized city-specific analyses may provide more information on social and biophysical vulnerability than larger, less spatially resolute studies at the regional and national levels [53]. Thus, vulnerability metrics should be aggregated at the city level, where decisions are more likely to reflect information on vulnerability within intra-urban populations and can therefore be the most informed methods of response [33]. Implementing vulnerability mapping techniques that incorporate social and biophysical vulnerabilities into a placebased, or location-specific, assessment allows for improved integration of historically disparate information. This can lead to improved implementation and monitoring of risk reduction policies within rapidly growing urban communities at the local level $[11,28,33]$.

\section{Satellite-Based Remote Sensing as a Surveillance Tool}

Remote sensing is the process of acquiring data about an area of interest without direct contact, be it one or $100 \mathrm{~m}$ way. Common examples of remote sensing include $\mathrm{X}$-rays, photography, and even human vision. These are all examples of practices that gather information from a distance, whether it is through a handheld device or incorporated into an orbiting satellite. For environmental research, the process is most similar to photography, where a sensor will "take a picture" of an area while recording data from within and outside the visual spectrum. Visual light is created by the Sun, which also emits other wavelengths of electromagnetic radiation (EMR), such as X-rays, infrared, thermal, and radio waves. Unlike the human eye, remote sensing devices can be calibrated to collect data across many diverse and distant wavelengths [25]. Analysts can use these multispectral, diverse wavelength images to interpret data not available to the human eye. A common application of nonvisual spectrum data is the use of thermal or infrared vision goggles. 
Remote sensing allows for the analysis of environmental features through imagery and quantitative calculations through pixel values. Thermal imagery, for example, can be used to distinguish areas of the city that have increased thermal characteristics through calculation of land surface temperature (LST) [27]. This technique is used to identify the UHI or the hot spots within a city that are disproportionally warmer than the surrounding features. Johnson et al. [26] summarizes various possibilities by including remotely sensed data to examine vulnerability (e.g., understanding the variability of heat between intra-urban neighborhoods). The application of remote sensing can also be useful for identifying other additional stress factors, such as a lack of vegetation. Plants can be responsible for reducing LST and filtering pollutants out of the atmosphere.

Photosynthetic vegetation utilizes blue, red, and thermal wavelengths of EMR during photosynthesis while reflecting green and near-infrared wavelengths. This process gives plants their green color. Since this process occurs in healthy, photosynthetic vegetation, the health and quantity of local vegetation can be calculated by creating an index from reflection measurements of red and near-infrared light $[19,25]$. This process is commonly utilized in remotely sensed projects and is known as the Normalized Difference Vegetation Index (NDVI). The higher NDVI value recorded, the more protection vegetation should provide, both through decreased thermal impact to the area and by filtering pollutants out of the air during respiration [11]. A similar scale, the Normalized Difference Built-up Index (NDBI), utilizes the reflection properties of cement and other constructed materials to identify areas of impervious surfaces. Higher NDBI values are normally associated with increased urban construction, which is linked to increased temperature, air pollutants, and precipitation runoff. Incorporating LST, NDVI, and NDBI allows for the consideration of environmental impacts on vulnerability-previous studies have not integrated environmental properties and socioeconomic vulnerability in this way [62]. These indices can be used to represent the influence-either positive or negative-of environmental variables on the vulnerability of local populations [28].

\section{An Example Methodology: Modeling Vulnerability to an Extreme Heat Event}

Vulnerability to EHEs is normally considered only from a statistical perspective. That is, an area is considered to be under extreme weather conditions when the weather station, commonly located outside the city limits, has observed adverse conditions (high temperature, high relative humidity, or a combination of these two) similar to historical events that had a statistical increase in mortality/morbidity. While this approach can be applicable to a broad understanding of a vulnerability event over a large area, such as a county or city boundary, it is insufficient for city planners and emergency management personnel to identify specific areas of high risk. Mitigation strategists and planners need a more detailed view of vulnerability. Hence, there is a trend in the research community to include environmental factors (provided by remotely sensed data) in combination with socioeconomic factors to 
understand vulnerability at a much finer scale [29, 53, 64]. Gauging vulnerability to EHEs is particularly challenging, because EHEs occur without clear warning signs. Other natural hazards, such as tornadoes or blizzards, approach as clouded weather fronts and are typically associated with drastic changes in wind and temperature. The public must rely on advisories, warnings, and watches issued by weather agencies to become aware of an EHE. As previously mentioned, these warnings are often based on data collected from a weather station located outside of the urban core, where temperatures are not as extreme. While the reported maximum temperature and heat index describe predicted temperatures across large urban areas, they do not represent the true exposure of various intra-urban areas to EHEs, because vulnerability to heat is not uniform across the entire urban space. For example, densely populated areas with old and dilapidated buildings, commonly found within inner city cores, may experience temperatures $3-5^{\circ}$ higher than what is indicated by the issued advisory recorded by the weather station [27].

Our research aims to (a) understand the spatial distribution of vulnerability for EHEs within an entire urban setting and (b) develop maps identifying areas of increased risk. In our method, socioeconomic data collected and disseminated by the US Census Bureau is combined with environmental factors (LST, NDVI, and NDBI) to generate an index representing the vulnerability of an enumeration unit (census block/block group/tract) during an EHE. Therefore, an accurate understanding of the spatial distribution of vulnerability is a useful tool for risk management and mitigation strategists. This index can be generated using either principal component analysis (PCA) or an artificial neural network (ANN) (Fig. 9.1).

\section{Vulnerability Indices Using Principal Component Analysis}

A method of data reduction is needed to better understand how the vulnerability input variables interact to create the severity of an area's risk. PCA can be used to identify the underlying constructs of the variables, identify trends, and designate which features are most important [12]. This method can be used to see which input variables are similar in order to create a simpler set of factors to represent the variables that most heavily affect vulnerability. Data reduction reduces the number of input variables in order to streamline calculations including many factors [30]. The PCA's data reduction method simplifies a multivariable dataset, by identifying the input variables' correlation among themselves. It then creates new factors by restructuring the data into new combined components that individually express a larger portion of the variance found in the original variables. PCA results can be compared between studies by the number of components they produce. The fewer components needed to demonstrate the variance, the more correlated/similar the original data is - and the stronger the model that is produced.

These components can be utilized in mapping EHE mitigation. If the components are plotted against a heat mortality-dependent value, the primary components will contain an identification of mortality risk. The components can then be mapped 


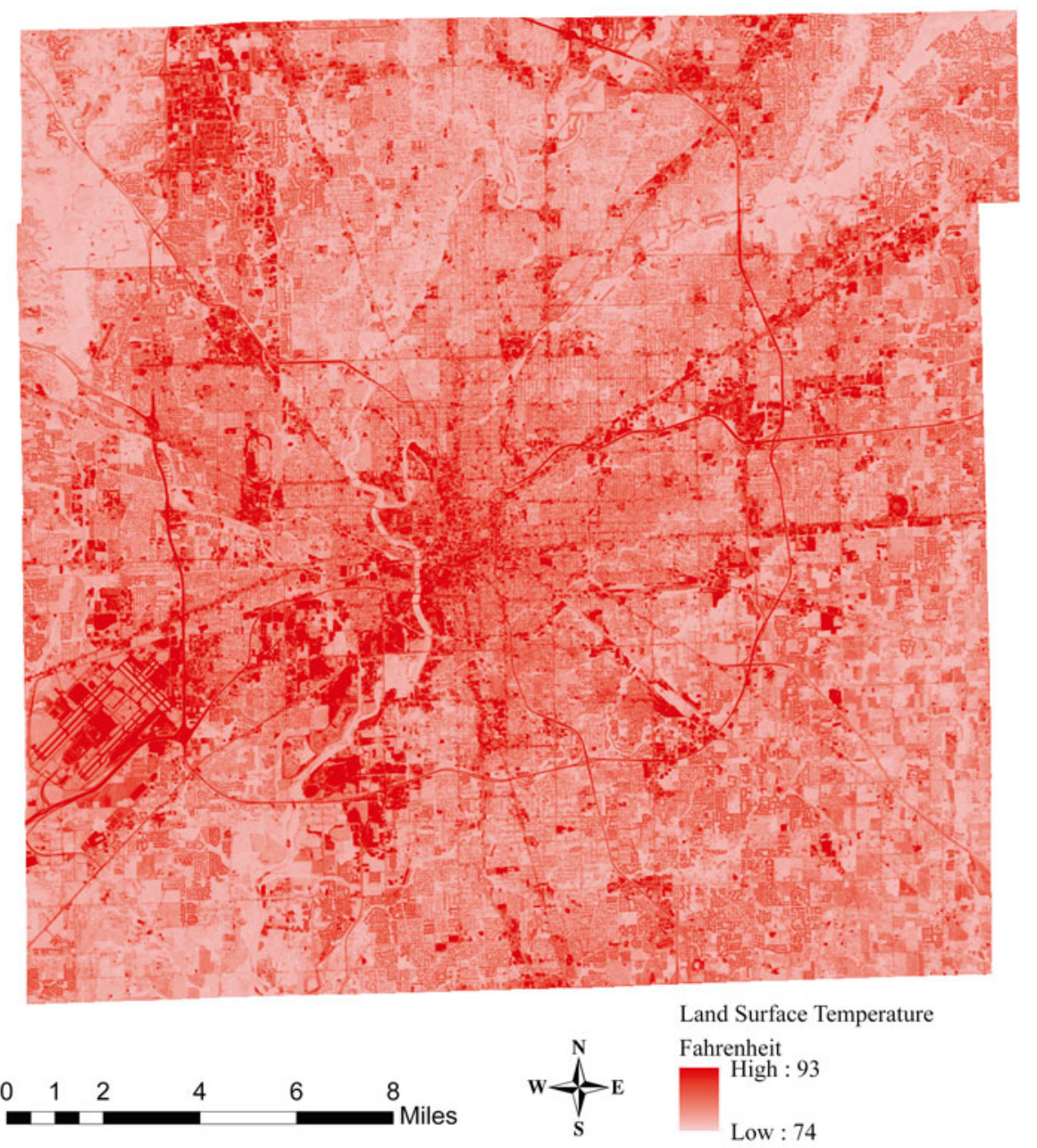

Fig. 9.1 LST image of Indianapolis, IN, acquired by the Landsat 5 TM satellite platform acquired on July 1, 2011

to identify areas that feature a majority of the characteristics related to heat mortality during an EHE.

The socioeconomic variables included in this model, extracted from decadal census data, include population counts by race, age, educational attainment, household income, and elderly living alone. These factors are combined with environmental factors (LST, NDVI, and NDBI) known to contribute to vulnerability. This analysis can be carried out at both the census tract and census block group enumeration levels, which are political boundaries based on population density. The output from this analysis yields an index of vulnerability. Organizing enumeration units into 


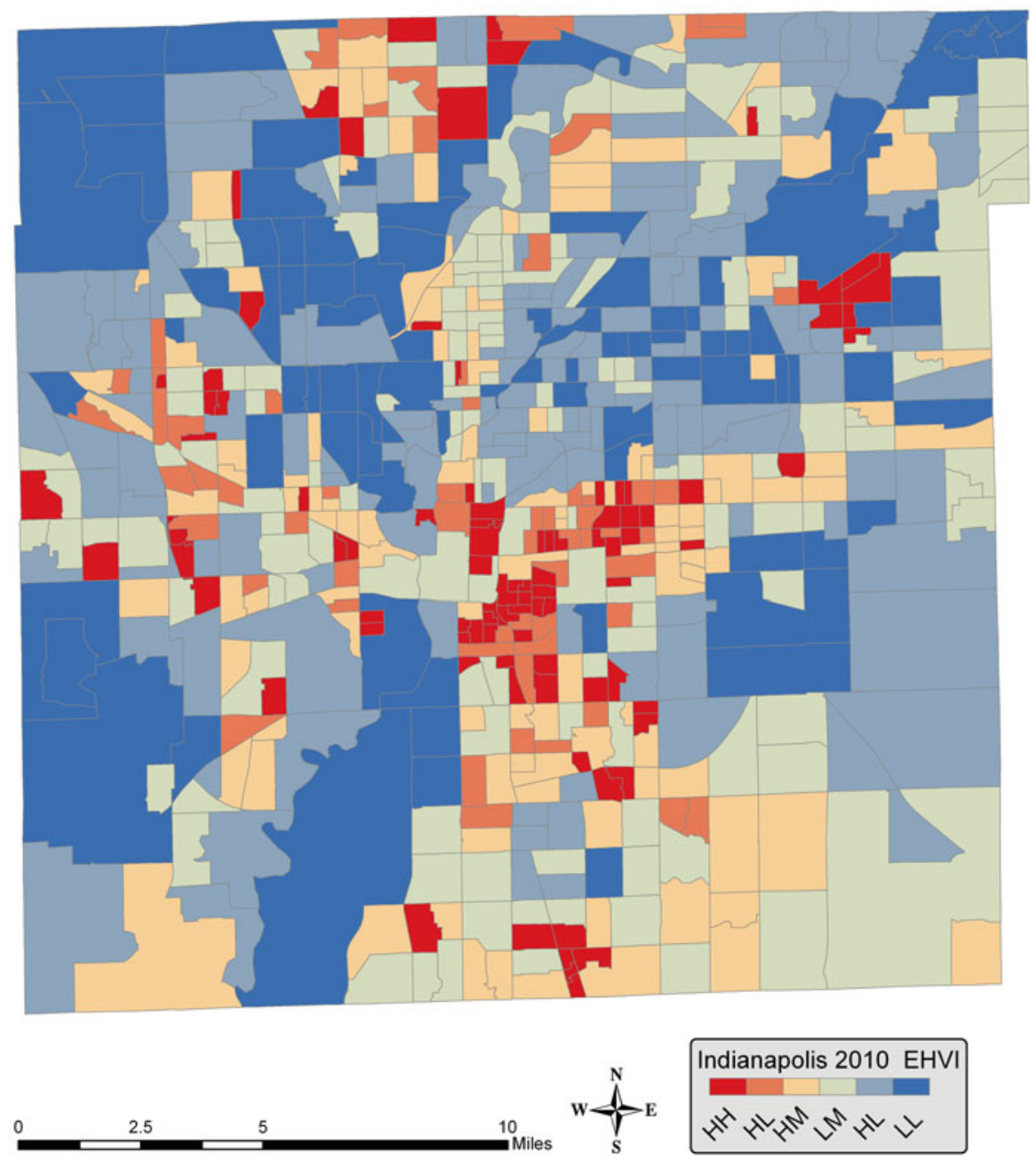

Fig. 9.2 An extreme heat vulnerability index analysis map of Indianapolis, IN, utilizing 2010 census socioeconomic data and environmental data collected by the Landsat 5 TM satellite on July 15,2011

classes based on this vulnerability score provides a clear picture of vulnerability levels across specific micropopulations. The analysis of the 1995 Chicago, IL, heat wave by Stanforth [62] is an example of how PCA can be used to determine vulnerability utilizing these input variables (see Fig. 9.2).

The study by Stanforth [62] also aimed to evaluate the significance of spatial resolution, and utilization of residential vs. commercial land use, for this type of analysis. The results supported the hypothesis that vulnerability to EHE mortality and morbidity can be appropriately measured and predicted within boundaries 
(census track and block groups) smaller than the county boundaries used in previous systems. The best explanation of variance for the study occurred during the census tract enumeration level of analysis, but was only a few percentage points better than the analysis using smaller block group enumeration levels. Although the census tract results contained a higher percent of variance explained, the block group analysis had fewer principal components. This demonstrates that the block group, smaller spatial boundary, PCA analysis resulted in components which were more correlated. This suggests that similar smaller-scale models could greatly improve spatial resolution, or accuracy, of the incorporated variables and results. The results demonstrated that, overall, vulnerability is very specific to certain socioeconomic variables and is very dependent on spatial resolution. This further suggests the need for increased spatial resolution of variables and analysis beyond the county boundary, which is used in most current NWS warnings and is an outdated method. New, spatially-specific warnings would have the potential to save more lives and reduce disaster response costs through improved mitigation practices.

\section{Vulnerability Using Artificial Neural Networks}

ANNs is a modeling method based on the principles of the biological neural network. ANN is a computational model comprised of a series of interconnected variables, or neurons/nodes, that model the relationship of data between the input and output parameters [36]. Just like the biological neural system, an ANN is composed of nodes, possibly in multiple layers, connected to a series of other nodes. ANN results are based on trained input-to-output connections, similar to repetition-based muscular training processes in biological creatures. The interconnectedness of the nodes results in a complex network comprising the ANN. ANNs are adaptive systems that operate in two phases: the learning (or training) phase and the testing/ predicting stage. During the learning/training phase, the network is provided with known input-output pairs to establish a relationship between input and output data.

Commonly, the connection between the two individual nodes is just a mathematical function $f: X \rightarrow Y$. Since each node is connected to many other nodes, the input to a node is the summation of all the incoming connections, and the output is the function $f$ applied to this summation [36]. The interconnectedness of the nodes provides an opportunity for modeling many different kinds of relationships, by changing the mathematical function used for the connections or by adjusting the weights to different inputs to precisely control the input of all the different inputs (Kohonen 1990). The connections between the nodes are adjusted so that the network converges toward, or learns, a model that is actually represented by the data. The number of nodes, number of layers, learning function, rate of learning, number of iterations required to converge on a solution, and least acceptable error are all parameters that can be modified, by trial and error, to develop a model to fit the study's requirements.

There has been a recent increase in ANN use, because they have some very useful characteristics. ANNs do not pose any restriction on the distribution characteristics of the collected data $[32,48]$. Linear regression, on the other hand, requires data 
used for modeling to be normally distributed. ANNs also allow the incorporation of many different types of variables (categorical, nominal, and/or ordinal data) to be included in the analysis [3, 7]. Finally, ANNs are not affected by variable outliers in the data as much as PCA. ANNs do, however, have some drawbacks. They are complicated and often require extensive setup to initiate. The final drawback is the issue of model over-fitting. Model over-fitting occurs when ANN trains noise to result's nodes along with the signal, when the number of input variables is larger than the number of training cases, and/or the input variables are highly correlated with each other $[56,60]$.

We describe below how we used ANN for some preliminary analysis. As described earlier, the input variables are comprised of socioeconomic and environmental factors. Mortality data was obtained from the respective cities, and only deaths related to the EHE were selected and geocoded, located spatially based on a postal address. The predicted number of aggregate deaths within each census enumeration unit (census tract or block group) was used as the output for the ANN. Once the model was created, after training and testing, it predicted the number of deaths per census boundary and compared them to recorded deaths from a historical EHE. The figures below show the neural network predicted mortalities compared to the actually observed mortality.

The difference in the scatter plots is due to the different number of enumeration units and different number of deaths for the cities of Dayton (a) and Phoenix (b) (Fig. 9.3). As can be seen from the images, the predicted mortality appears to follow the trend of observed mortality. This suggests a strong positive predictive ability of the ANN and suggests a possibility of improving the neural network model, either by tweaking the parameters used during training or refining the data by incorporating only residential areas, as demonstrated by Stanforth [62].
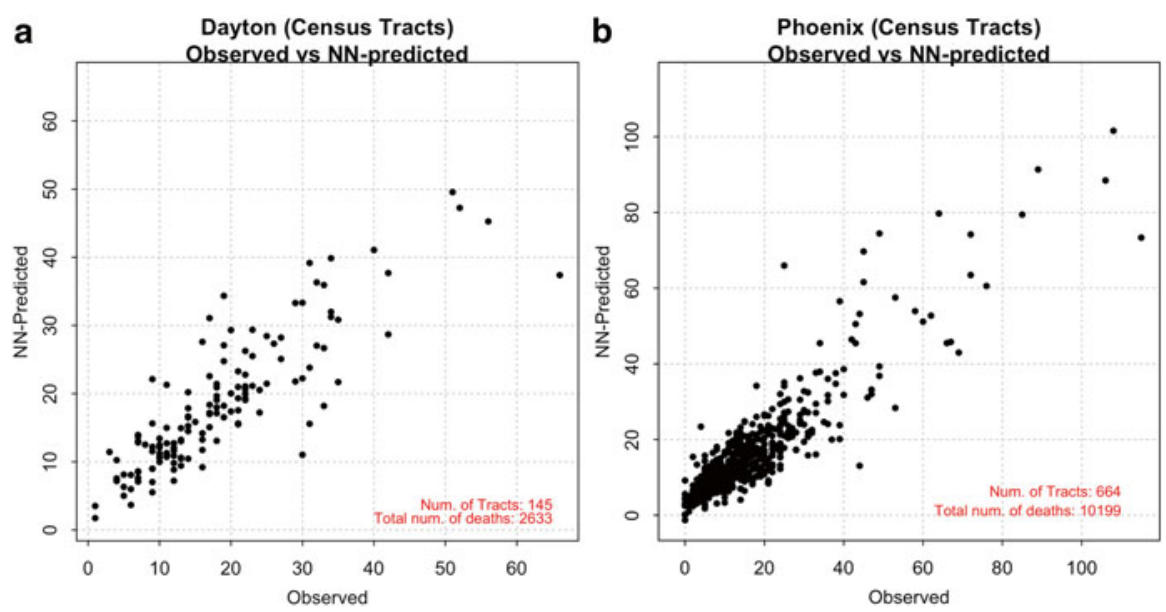

Fig. 9.3 Scatter plot of NN predicted vs. observed mortality for (a) Dayton and (b) Phoenix. Analysis was carried out at census tract enumeration level 


\section{Future Directions for Research and Improvement}

\section{Hyperspectral Remote Sensing}

As discussed earlier, satellite-based remotely sensed data is now commonly used in modeling vulnerability, but there are limitations to the use of such data. First, temporal resolution, or frequency at which the data is collected, does not allow for continuous measurement, as the sensor is only in position a couple days per month. For example, the temporal resolution for Landsat data is 16 days; in other words, an image is taken at the same location once every 16 days and will sometimes miss the heat wave window or be blocked by cloud cover. There are some satellites that have a temporal resolution of one day, but their spatial resolution is too coarse to be of much use for the study of intra-urban areas. Aircraft-based hyperspectral remote sensors can alleviate both the issues of spatial and temporal resolution. Hyperspectral remote sensors are very analogous to their multispectral counterparts, but differ in that they measure the electromagnetic reflectance in very narrow, contiguous bands. This provides a much more representative sample of the reflectance curve of the underlying feature. The spatial resolution of aircraft-collected data can also be much better than the satellite-based multispectral data, depending on the altitude at which the aircraft passes over the area of interest. This availability of higher spectral and spatial resolution provides more fine-grained data, which can improve the performance of models using this data. The methods and techniques used for hyperspectral analysis are slightly different than those for multispectral data. Increased spectral bands require higher computer processing power, and the preprocessing methods are also different. Since hyperspectral data are aircraft collected, they contain errors attributable to the movement of the aircraft (roll, yaw, and pitch). These errors need to be removed by preprocessing the data. This is not a complicated problem, as most of these sensors come with utilities and tools with customizable settings for each flight, allowing for correction of errors later on. Still, hyperspectral sensors are very expensive; therefore, they not practical for widespread use.

\section{Web-Based Modeling Tools}

While most vulnerability-related modeling is carried out in university labs and research centers, there is a possibility of creating a Web-based tool/framework. This tool could be specifically designed to allow local planners to input data for their localities and generate vulnerability maps for planning and mitigation purposes. This Web interface could allow a municipality to identify areas at an increased risk to weather disasters and to efficiently distribute the data and test/implement mitigation plans. In a digital format, the application could allow the vulnerability maps to be distributed to hospitals or nonprofit groups so that medical assistance could be positioned in high-risk areas before the adverse conditions occur. The application could also allow city planners to test how a new mitigation practice would impact risk, such as planting trees in areas of high UHI. The Web application could also 
allow for the quick update of data during oppressive seasons. If a wild fire or tornado destroyed a large portion of the urban canopy, as during the 2011 Alabama disasters, new mitigation maps could be produced "on the fly" to assist with the cleanup and preparation for the next disaster. Work is currently being conducted on creating such a Web framework used for generating EHE vulnerability maps specific to a city or county.

\section{Concluding Remarks}

With increased awareness about climate change and its impact on the environment and society, there is an ongoing trend to move toward collaboration among different areas of the research community. While vulnerability has traditionally been studied primarily by sociologists, it now involves researchers from diverse fields who aim to collect, analyze, and model data in new and meaningful ways. These collaborations present a unique opportunity to better understand and model vulnerability through more comprehensive studies. While only EHE has been discussed in this chapter, these same principles can be applied to model vulnerability to other natural and anthropogenic hazards throughout the developed and developing world. The procedures previously described for heat mitigation could be adapted easily to cold weather disasters as well or be utilized to create location-specific mitigation plans for flash flooding and identification of Lyme disease-infested tick populations. Understanding the improved benefits of incorporating environmental and societal risk elements has provided a new holistic view of vulnerability. This view will hopefully lead us to a safer and more prepared future.

\section{References}

1. Arnfield AJ. Two decades of urban climate research: a review of turbulence, exchanges of energy and water, and the urban heat island. Int J Climatol. 2003;23:1-26.

2. Bell ML, Dominici F, Samet JM. A meta-analysis of time-series studies of ozone and mortality with comparison to the national morbidity, mortality, and air pollution study. Epidemiology. 2005; 16:436.

3. Benediktsson JA, Swain PH, Ersoy OK. Neural network approaches versus statistical methods in classification of multisource remote sensing data. IEEE Trans Geosci Remote Sens. 1990;28:540-52.

4. Braham R. Cloud physics of urban weather modification-a preliminary report. Bull Am Meteorol Soc. 1974;55:100-6.

5. Braham RR, Semonin R, Auer AH, Changnon SA, Hales JM. Summary of urban effects on clouds and rain. In: Changnon SA, editor. METROMEX: a review and summary. Boston: American Meteorological Society; 1981. p. 141-52.

6. Burian SJ, Shepherd JM. Effect of urbanization on the diurnal rainfall pattern in Houston. Hydrol Process. 2005;19:1089-103.

7. Carpenter GA, Gopal S, Macomber S, Martens S, Woodcock CE, Franklin J. A neural network method for efficient vegetation mapping. Remote Sens Environ. 1999;70:326-38. 
8. Confalonieri U, Menne B, Akhtar R, Ebi KL, Hauengue M, Kovats RS, et al. Human health. In: Parry ML, Canziani OF, Palutikof JP, Van der Linden PJ, Hanson CE, editors. Climate change 2007: impacts, adaptation and vulnerability. Contribution of working group II to the fourth assessment report of the intergovernmental panel on climate change. Cambridge: Cambridge University Press; 2007. p. 391-431.

9. Cotton WR, Pielke RA. Human impacts on weather and climate. New York: Cambridge University Press; 1995.

10. Curriero FC, Patz JA, Rose JB, Lele S. The association between extreme precipitation and waterborne disease outbreaks in the United States, 1948-1994. Am J Public Health. 2001;91:1194-9.

11. Cutter SL, Boruff BJ, Shirley WL. Social vulnerability to environmental hazards*. Soc Sci Q. 2003;84:242-61.

12. DeCoster J. Data analysis in SPSS. 2004. http://www.stat-help.com/notes.html. Accessed 31 May 2011.

13. Degaetano AT. Meteorological effects on adult mosquito (Culex) populations in metropolitan New Jersey. Int J Biometeorol. 2005;49:345-53.

14. Dominici F, Peng RD, Bell ML, Pham L, Mcdermott A, Zeger SL, Samet JM. Fine particulate air pollution and hospital admission for cardiovascular and respiratory diseases. JAMA. 2006;295:1127-34.

15. Ebi K, Balbus J, Kinney P, Lipp E, Mills D, O’Neill M, et al. Synthesis and assessment product 4.6: chapter 2, effects of global change on human health (final review draft). CCSP; 2008.

16. Frumkin H, Hess J, Luber G, Malilay J, Mcgeehin M. Climate change: the public health response. Am J Public Health. 2008;98:435.

17. Gaffield SJ, Goo RL, Richards LA, Jackson RJ. Public health effects of inadequately managed stormwater runoff. Am J Public Health. 2003;93:1527.

18. Gage KL, Burkot T, Eisen RJ, Hayes EB. Climate change and vector-borne diseases. Am J Prev Med. 2008;35:436-50.

19. Glenn EP, et al. Relationship between remotely-sensed vegetation indices, canopy attributes and plant physiological processes: what vegetation indices can and cannot tell us about the landscape. Sensors 8.4. 2008: 2136-2160.

20. Gryparis A, Forsberg B, Katsouyanni K, Analitis A, Touloumi G, Schwartz J, Samoli E, Medina S, Anderson HR, Niciu EM. Acute effects of ozone on mortality from the "air pollution and health: a European approach" project. Am J Respir Crit Care Med. 2004;170: $1080-7$.

21. Haines A, Patz JA. Health effects of climate change. JAMA. 2004;291:99-103.

22. Harlan SL, Brazel AJ, Prashad L, Stefanov WL, Larsen L. Neighborhood microclimates and vulnerability to heat stress. Soc Sci Med. 2006;63:2847-63.

23. Hughes $\mathrm{K}$. The impact of urban areas on climate in the UK: a spatial and temporal analysis, with an emphasis on temperature and precipitation effects. Earth Environ. 2006;2:54-83.

24. Ito K, De Leon SF, Lippmann M. Associations between ozone and daily mortality: analysis and meta-analysis. Epidemiology. 2005;16:446.

25. Jensen JR. Remote sensing of the environment: an earth resource perspective. Upper Saddle River: Pearson Prentice Hall; 2007.

26. Johnson DP, Lulla V, Stanforth AC, Webber J. Remote sensing of heat-related risks: the trend towards coupling socioeconomic and remotely sensed data. Geogr Compass. 2011;5(10): 767-80. doi: 10.1111/j.1749-8198.201.00442.x.

27. Johnson DP, Stanforth AC, Lulla V, Luber G. Developing an applied extreme heat vulnerability index utilizing socioeconomic and environmental data. Appl Geogr. 2012;35(1-2):23-31. ISSN 0143-6228, 10.1016/j.apgeog.2012.04.006.

28. Johnson DP, Wilson JS. The socio-spatial dynamics of extreme urban heat events: the case of heat-related deaths in Philadelphia. Appl Geogr. 2009;29:419-34.

29. Johnson D, Wilson J, Luber G. Socioeconomic indicators of heat-related health risk supplemented with remotely sensed data. Int J Health Geogr. 2009;8:57. 
30. Jolliffe I. Principal component analysis. New York: Wiley; 2002.

31. Kalkstein LS, Greene JS. An evaluation of climate/mortality relationships in large US cities and the possible impacts of a climate change. Environ Health Perspect. 1997;105:84.

32. Kanellopoulos I, Wilkinson GG. Strategies and best practice for neural network image classification. Int J Remote Sens. 1997;18:711-25.

33. Kienberger S, Lang S, Zeil P. Spatial vulnerability units? Expert-based spatial modelling of socio-economic vulnerability in the Salzach catchment, Austria. Nat Hazards Earth Syst Sci. 2009;9:767-78.

34. Kinney PL. Climate change, air quality, and human health. Am J Prev Med. 2008;35:459-67.

35. Kohonen T. Self-organized formation of topologically correct feature maps. Biol Cybern. 1982;43:59-69.

36. Kohonen T. Self-organization and associative memory. Berlin: Springer; 1989.

37. Kovats S, Akhtar R. Climate, climate change and human health in Asian cities. Environ Urban. 2008;20:165-75.

38. Kunkel KE, Novak RJ, Lampman RL, Gu W. Modeling the impact of variable climatic factors on the crossover of Culex restauns and Culex pipiens (Diptera: Culicidae), vectors of West Nile virus in Illinois. Am J Trop Med Hyg. 2006;74:168-73.

39. Laden F, Schwartz J, Speizer FE, Dockery DW. Reduction in fine particulate air pollution and mortality. Am J Respir Crit Care Med. 2006;173:667-72.

40. Landsberg HE. The urban climate. New York: Academic; 1981.

41. Levy JI, Chemerynski SM, Sarnat JA. Ozone exposure and mortality: an empiric Bayes metaregression analysis. Epidemiology. 2005;16:458.

42. Mccabe GJ, Bunnell JE. Precipitation and the occurrence of Lyme disease in the northeastern United States. Vector Borne Zoonotic Dis. 2004;4:143-8.

43. Mudway I, Kelly F. Ozone and the lung: a sensitive issue. Mol Aspects Med. 2000;21:1-48.

44. O’Neill M, Jackman D, Wyman D, Manarolla X, Gronlund C, Brown D, Brines S, Schwartz J, Diez-Roux A. US local action on heat and health: are weprepared for climate change? Int $\mathrm{J}$ Public Health. 2010;55:105-12.

45. Oke TR. Boundary layer climates. New York: Psychology Press; 1988.

46. Oke TR, editor. Urban climates and global environmental change. London: Routledge; 1997.

47. Ostfeld RS, Canham CD, Oggenfuss K, Winchcombe RJ, Keesing F. Climate, deer, rodents, and acorns as determinants of variation in Lyme-disease risk. PLoS Biol. 2006;4:e145.

48. Paola JD, Schowengerdt RA. A review and analysis of backpropagation neural networks for classification of remotely-sensed multi-spectral imagery. Int J Remote Sens. 1995;16: 3033-58.

49. Pope III CA, Burnett RT, Thun MJ, Calle EE, Krewski D, Ito K, Thurston GD. Lung cancer, cardiopulmonary mortality, and long-term exposure to fine particulate air pollution. JAMA. 2002;287:1132-41.

50. Pope III CA, Burnett RT, Thurston GD, Thun MJ, Calle EE, Krewski D, Godleski JJ. Cardiovascular mortality and long-term exposure to particulate air pollution epidemiological evidence of general pathophysiological pathways of disease. Circulation. 2004;109:71-7.

51. Prospero JM, Lamb PJ. African droughts and dust transport to the Caribbean: climate change implications. Science. 2003;302:1024-7.

52. Purse BV, Mellor PS, Rogers DJ, Samuel AR, Mertens PPC, Baylis M. Climate change and the recent emergence of bluetongue in Europe. Nat Rev Microbiol. 2005;3:171-81.

53. Reid CE, O’Neill MS, Gronlund CJ, Brines SJ, Brown DG, Diez-Roux AV, Schwartz J. Mapping community determinants of heat vulnerability. Environ Health Perspect. 2009;117: 1730.

54. Rose JB, Epstein PR, Lipp EK, Sherman BH, Bernard SM, Patz JA. Climate variability and change in the United States: potential impacts on water-and foodborne diseases caused by microbiologic agents. Environ Health Perspect. 2001;109:211.

55. Samet JM, Dominici F, Curriero FC, Coursac I, Zeger SL. Fine particulate air pollution and mortality in 20 US cities, 1987-1994. N Engl J Med. 2000;343:1742-9. 
56. Sarle WS. Stopped training and other remedies for overfitting. In: Proceedings of the 27th symposium on the interface of computing science and statistics. 1995.

57. Schwartz J. Short term fluctuations in air pollution and hospital admissions of the elderly for respiratory disease. Thorax. 1995;50:531-8.

58. Shea KM, Truckner RT, Weber RW, Peden DB. Climate change and allergic disease. J Allergy Clin Immunol. 2008;122:443-53.

59. Shone SM, Curriero FC, Lesser CR, Glass GE. Characterizing population dynamics of Aedes sollicitans (Diptera: Culicidae) using meteorological data. J Med Entomol. 2006;43:393-402.

60. Smith M. Neural networks for statistical modeling. Boston: International Thomson Computer Press; 1996.

61. Smoyer KE. Putting risk in its place: methodological considerations for investigating extreme event health risk. Soc Sci Med. 1998;47:1809-24.

62. Stanforth A. Identifying variations of socio-spatial vulnerability to heat-related mortality during the 1995 extreme heat event in Chicago, IL, USA. M.S. Thesis. IUPUI: USA. 2011. http:// hdl.handle.net/1805/2643.

63. Thielen J, Wobrock W, Gadian A, Mestayer P, Creutin JD. The possible influence of urban surfaces on rainfall development: a sensitivity study in $2 \mathrm{D}$ in the meso-[gamma]-scale. Atmos Res. 2000;54:15-39.

64. Uejio CK, Wilhelmi OV, Golden JS, Mills DM, Gulino SP, Samenow JP. Intra-urban societal vulnerability to extreme heat: the role of heat exposure and the built environment, socioeconomics, and neighborhood stability. Health Place. 2011;17:498-507.

65. Vescovi L, Rebetez M, Rong F. Assessing public health risk due to extremely high temperature events: climate and social parameters. Climate Res. 2005;30:71.

66. Wegbreit J, Reisen WK. Relationships among weather, mosquito abundance, and encephalitis virus activity in California: Kern County 1990-98. J Am Mosq Control Assoc. 2000;16:22-7.

67. WHO. Preventing harmful health effects of heat-waves. Copenhagen: World Health Organization; 2006.

68. WMO. Climate and urban development. WMO no. 844. 1996. 